\title{
An Approach to Increase Energy Efficiency Using Shutdown and Standby Machine Modes
}

\author{
Apostolos Fysikopoulos, Georgios Pastras, \\ Aikaterini Vlachou, and George Chryssolouris* \\ Laboratory for Manufacturing Systems and Automation, \\ Department of Mechanical Engineering and Aeronautics, \\ University of Patras, Patras 26500, Greece \\ xrisol@lms.mech. upatras.gr.
}

\begin{abstract}
Energy efficiency constitutes a very significant factor that requires its inclusion in the manufacturing decision making attributes developing a strategy to produce more with less. The idle state of a machine tool is an inefficient phase. A strategy to increase the energy efficiency of an already balanced production line, using machine tool stand-by or shut-down modes, during the idle phase, is being introduced. This strategy identifies when the application of such modes is gainful from an energy efficiency point of view, based on the available idle time and the consumption of the machine at these modes.
\end{abstract}

Keywords: Energy Efficiency, Sustainable Manufacturing, Machine Tools, Production Planning, Scheduling.

\section{Introduction}

The manufacturing industry is one of the greatest energy consumers and carbon emitters in the world [1]. The manufacturing sector is responsible for about $28 \%$ of the primary energy use [3] and for $38 \%$ of the $\mathrm{CO}_{2}$ emissions globally [2]. Thus, energy and eco-efficiency has emerged as one of the most significant manufacturing decision attributes [4], especially in countries that are not energy independent [5]. Additionally, energy is an increasingly important cost factor due to its increasing price [6]. Manufacturing enterprises have to reduce energy consumption for both cost saving and environmental friendliness, trying to find new ways to produce "more with less" [7] and furthermore, evolve from the strategy "maximum gain from minimum capital" to "maximum gain from minimum resources" [8].

Several initiatives on energy efficiency are on-going [9-11]. Energy saving management, technologies and policies/regulations [12] are used to deal with the energy efficiency issues [13].

The study of energy efficiency in manufacturing systems can be divided into four main levels (Fig. 1) [4]. The study of each level and their inter-level interactions are important steps towards the effective study of energy and eco-efficiency hence, the need for a holistic approach is necessary $[4,14]$.

\footnotetext{
* Corresponding author.

B. Grabot et al. (Eds.): APMS 2014, Part II, IFIP AICT 439, pp. 205-212. 2014.

(C) IFIP International Federation for Information Processing 2014
} 


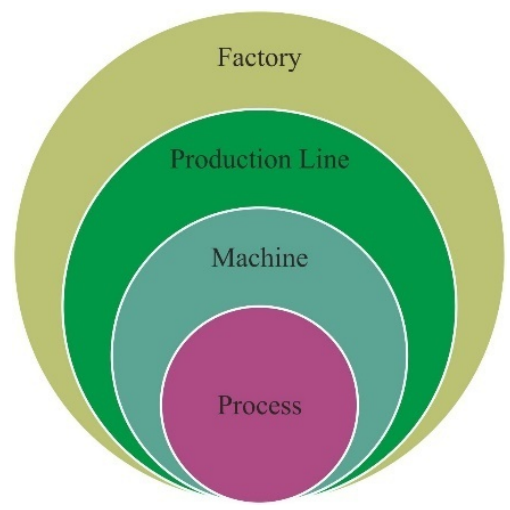

Fig. 1. Energy efficiency analysis division [4]

\section{$2 \quad$ Energy Efficiency at Production Line Level}

Decisions on planning and operating production systems are mainly based on traditional metrics such as time, cost, quality and flexibility [15]. In terms of energy cost, a limited number of studies regarding time-dependent industrial planning, under the point of view of electricity cost, have been reported [17-19].

Several reviews on commercially available manufacturing simulation tools reveal that they do not support energy and eco-efficiency indicators yet [20-22]. Fysikopoulos et al. [16] have incorporated simple energy formulas into a "real life" automotive assembly line, with the use of discrete event simulation (DES). DES in combination with the life cycle assessment (LCA) method was presented by Johanson et al. [23]. With the help of this model, the energy aspects of the line along with other performance measures, have been investigated. Wohlgemuth et al. [22] suggested an approach for the integration of DES and the material flow analysis into a component-based framework, based on a single model towards a customized Environmental Management Information System (EMIS). In this framework, production processes and all kinds of energy and material flows can be analysed in terms of both economic measures and their environmental impacts. Herrmann et al. [20] presented an energy oriented simulation model for the planning of manufacturing systems. They reported up to $30 \%$ improvement in energy efficiency through simulation-assisted process planning.

Mouzon et al. [24] developed mathematical multi-objective models to investigate the problem of scheduling jobs, on a single CNC machine, towards the reduction of time and energy consumption. An impressive outcome is the finding that when a nonbottlenecked machine is turned-off, the energy consumption savings may reach even $80 \%$. Additionally, by forecasting the inter-arrival time of the orders, significant savings can be achieved with the use of proper dispatching rules. Other studies focus on social and environmental issues and not just on energy consumption [25-28].

It is evident $[4,16,29,30,31]$ that the reduction of the idle time can significantly assist towards energy and eco-efficiency. Drake et al. [32] have reported significant 
energy consumption during machine idle time. As presented in [30, 33], in a production machine tool and generally in a mass production environment, the percentage of energy used for functions that are not directly related to the actual production of parts, may be as high as $85 \%$ or even more. However, "correct" order distribution (better batch and orders organization) combined with early or periodical "machine shut down" can considerably reduce the idle time, which is the most inefficient state of a system [4]. Additionally, the incorporation of energy consumption measuring, peak power management, monitoring, controlling and scheduling may lead to better prediction of the workflow and thus, to improved energy savings [4, 34, 35]. Thanks to the Information and Communication Technologies (ICT), innovative production management systems can be built to support energy efficient manufacturing [36].

\section{$3 \quad$ Machine Tools and Energy Efficiency}

The demand for greener machine tools creates new challenges for the machine tool builders. The state of the art in machine tools is the use of energy-efficient components that can reduce energy consumption during idle times up to 65\% [29]. Several studies on the energy efficiency of machine tools exist, regarding both conventional and non-conventional processes [30, 37, 38]. Besides the process variables optimisation, the development of energy and eco-efficient components is a basic task for machine tool builders [34].

The first step towards improving the energy efficiency of machine tools is the identification of the power requirements for different machine tool activities and the categorization of the peripheral devices. Fysikopoulos et al. [4] indicated that the actual consumed energy required for processing is exceeded to a great extent by the energy demand of the related peripheral equipment, especially for the laser based processes. The analysis can become complex, since several peripherals may be shared among different machines in the factory. Furthermore, they concluded that the consumption of machine peripherals per manufactured part depends on process variables through factors such as process time. Moreover, the overall energy consumption can be significantly reduced, if during idle times, the peripherals go to a complete off or standby phase (energy-saving mode) by integrating simple technological features. Nowadays, machine tool controls are equipped with the possibilities of switching the machine into energy-saving modes or even to shutting it down completely [39-41]. These new machine tool capabilities can be used for the significant reduction of a production line's energy consumption.

\section{$4 \quad$ A Strategy to Gain Energy Using Shut-down and Stand-by (energy-saving) Modes}

In practice, it is not possible to perfectly match the output rates of all the resources in a flow line thus, at least some resources remain idle for some time. The issue is to implement shut-down and stand-by modes in a production line which has already 
being optimised in terms of idle time. It has to be noted that the incorporation of such modes is not always gainful and actually, it may not even be possible, depending on the idle time available. While a machine is in idle mode, it usually consumes a constant power $\left(P_{\text {idle }}\right)$. Thus, the energy wasted in the idle mode is equal to $E_{\text {idle }}=P_{\text {idle }} t$, where $t$ is the idle time available.

Provided that the machine was switched-off, this constant consumption would have been avoided; however, there would be a period of maximum power consumption, necessary to start up the machine for its next task. It is assumed that the duration of the shut-down and start-up procedures is equal to $t_{\text {startup }}$ and that the corresponding

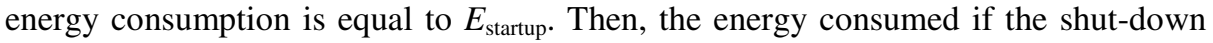
mode is used equals $E_{\text {shutdown }}=E_{\text {startup }}$ and it is possible only if the time available is larger than $t_{\text {startup. }}$. From the above arguments, it is evident that the incorporation of the shut-down mode is profitable only when $E_{\text {shutdown }}<E_{\text {idle, }}$ which is equivalent to the available time being larger than a critical value equal to

$$
t_{c r}=\frac{E_{\text {startup }}}{P_{\text {idle }}} \text {. }
$$

Similarly, an intermediate stand-by (energy-saving) mode can be incorporated. In such a mode, some of the machine's peripheral systems are turned off, while the more critical ones remain operative. Such a mode is characterized by some constant power consumption $P_{\text {standby }}$, smaller than $P_{\text {idle }}$, while the machine remains in stand-by mode. However, some time and energy is also required in order for the machine to "sleep" and then become operative again, namely $t_{\text {wake }}$ and $E_{\text {wake. }}$ If both stand-by and shutdown modes are available, it is typically true that $E_{\text {wake }}<E_{\text {startup }}$ and $t_{\text {wake }}<t_{\text {startup. The }}$ energy consumed if the standby mode is used equals $E_{\text {standby }}=E_{\text {wake }}+P_{\text {standby }}\left(t-t_{\text {wake }}\right)$. The stand-by mode can be used only if the available time is larger than $t_{\text {wake. }}$. Similarly to what is stated above for the shut-down mode, the stand-by mode is preferable to the idle mode provided that the available time is larger than

$$
t_{c r 1}=\frac{E_{\text {wake }}-P_{\text {standby }} t_{\text {wake }}}{P_{\text {idle }}-P_{\text {standby }}}
$$

and preferable to the shut-down mode if the available time is smaller than

$$
t_{c r 2}=\frac{E_{\text {startup }}-E_{\text {wake }}}{P_{\text {standby }}}+t_{\text {wake }} \text {. }
$$

It has to be noted that a standby mode is never profitable if $t_{c r 1}>t_{c r 2}$.

All the above arguments are summarized in Fig. 2. 


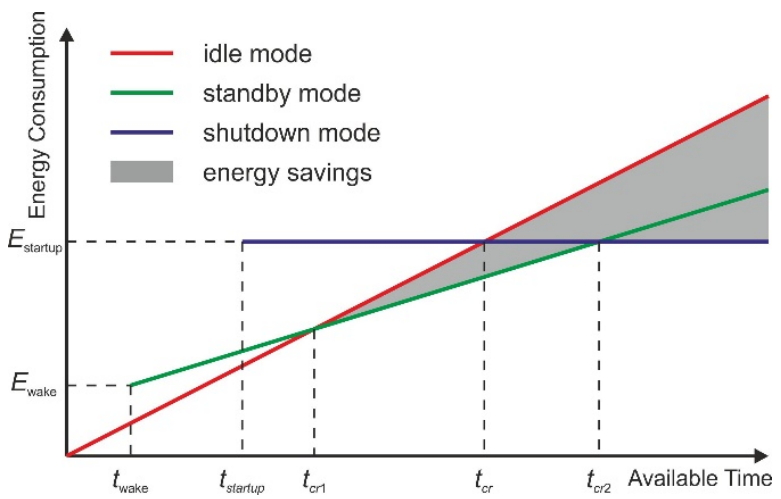

Fig. 2. An indicative diagram for the energy consumption of a machine during non-working time periods under different available modes

According to what was analysed above, a strategy to gain energy using the shutdown and stand-by modes can be specified. For every machine, the idle time durations predicted by suitable simulation method have to be compared with the critical times $t_{c r 1}$ and $t_{c r 2}$ and then the resource has to:

1. be shut-down, if the idle time is larger than $t_{c r 2}$

2 . be switched to stand-by mode, if the idle time lies between $t_{c r 1}$ and $t_{c r 2}$

3. remain idle, if the idle time is smaller than $t_{c r 1}$

The procedure has to be repeated for every resource. A logical diagram showing the above for a system consisting of $N$ resources is depicted in Fig. 3. It has to be noted that in the proposed method, the shutting-down or switching to a stand-by mode is not performed manually, but on the contrary, these actions are scheduled during the production planning stage.

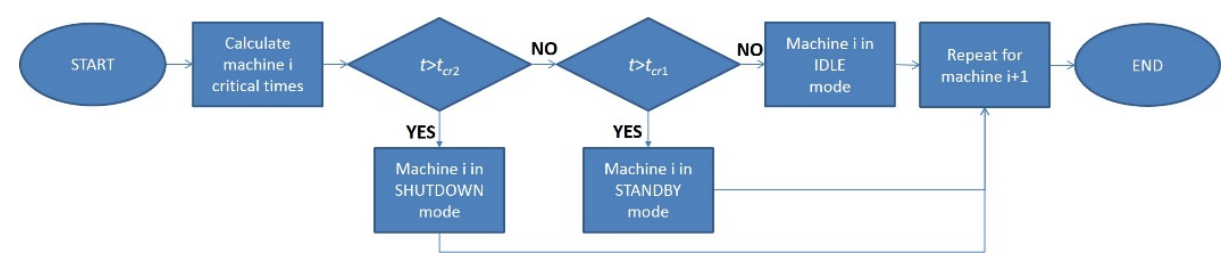

Fig. 3. A basic logic diagram describing the decision process for incorporation of shut-down and stand-by modes

\section{Conclusions}

In this study, a strategy to increase the energy efficiency of an already balanced production line, using the machine's tool stand-by (energy saving) or shut-down (completely turned-off) modes, during idle time, was introduced. The main outcomes can be summarised as following: 
- Energy efficiency metrics should be included in the commercially available multiobjective optimization decision support systems.

- Application of the shut-down or stand-by modes is not always profitable. It depends on the available idle time, the energy consumption for starting up and waking up, as well as the power consumption during the idle and stand-by modes, as described in Section 4 and depicted in Fig. 2.

- Application of the shut-down or stand-by modes can be gainful in terms of energy and consequently, in terms of the related energy costs.

- Since the inclusion of energy saving modes in the production schedule can be gainful, the machine tool builders should incorporate the required simple technological features into their machines.

- Machine tool builders should be careful when incorporating a stand-by function into their machines. Depending on the stand-by power consumption and the necessary wake-up energy, the use of this mode may never be preferable over the idle or shut-down mode (when $t_{c r 1}>t_{c r 2}$ ).

Future work will focus on methods to arrange the schedule of a production line so that the duration of the idle states is allowing the use of energy saving modes. Such methods will lead to maximum utilisation of these modes and thus, of the related energy and energy cost gains. Moreover, the method is going to be validated in a real industrial case study.

Acknowledgements. The work reported in this paper was supported by the collaborative program entitled "Energy Efficient Process planning System - ENEPLAN", which is under the seventh framework program - FoF.NMP.2011-1: The Eco-Factory: cleaner and more resource-efficient production in manufacturing Program.

\section{References}

1. International Energy Agency.: Worldwide Trends in Energy Use and Efficiency (2008)

2. Energy Information Administration.: Annual Energy Review (2011)

3. International Energy Agency.: World Energy Outlook (2012)

4. Fysikopoulos, A., Papacharalampopoulos, A., Pastras, G., Stavropoulos, P., Chryssolouris, G.: Energy Efficiency of Manufacturing Processes: A Critical Review. In: Procedia CIRP 2013, vol. 7, pp. 628-633 (2013)

5. Seow, Y., Rahimifard, S.: A framework for modelling energy consumption within manufacturing systems. CIRP J. Manuf. Sci. Technol. 4(3), 258-264 (2011)

6. Moreno, B., López, A.J., García-Álvarez, M.T.: The electricity prices in the European Union. The Role of Renewable Energies and Regulatory Electric Market Reforms 48(1), 307-313 (2012)

7. Chryssolouris, G., Papakostas, N., Mavrikios, D.: A perspective on manufacturing strategy: Produce more with less. CIRP J. Manuf. Sci. Tech. 1(1), 45-52 (2008)

8. International Energy Agency, Tracking Industrial Energy Efficiency and $\mathrm{CO} 2$ Emissions (2007) 
9. Directive 2009/125/EC of the European Parliament and of the Council of 21, establishing a framework for the setting of ecodesign requirements for energy-related products. Off. J. Eur. Union, 10-35( (October 2009)

10. Cooperative Effort on Process Emissions in Manufacturing CO2PE!, http: / / www. mech. kuleuven. be/co2pe/index.php (accessed: April 23, 2014)

11. CIRP Collaborative Working Group.: Energy and Resource Efficiency \& Effectiveness, http: / /www. cirp-eree. iwf.tu-bs. de (accessed: April 23, 2014)

12. Bruzzone, A.A.G., Anghinolfi, D., Paolucci, M., Tonelli, F.: Energy-aware scheduling for improving manufacturing process sustainability: A mathematical model for flexible flow shops. CIRP Ann. - Manuf. Technol. 61(1), 459-462 (2012)

13. Schlosser, R., Klocke, F., Lung, D.: Sustainabilty in Manufacturing: Energy Consumption of Cutting Processes. In: Advances in Sustainable Manufacturing, pp. 85-89 (2001)

14. Herrmann, C., Kara, S., Thiede, S., Luger, T.: Energy Efficiency in Manufacturing: Perspectives from Australia and Europe

15. Chryssolouris, G.: Manufacturing systems: theory and practice, 2nd edn. Springer (2006)

16. Fysikopoulos, A., Anagnostakis, D., Salonitis, D., Chryssolouris, G.: An Empirical Study of the Energy Consumption in Automotive Assembly. In: Procedia CIRP, vol. 3, pp. 477-482 (2012)

17. Nilsson, K., Soderstrom, N.: Industrial Applications of Production Planning with Optimal Electricity Demand. Appl. Energy 46(2), 181-192 (1993)

18. Yusta, J.M., Torres, F., Khodr, H.M.: Optimal methodology for a machining process scheduling in spot electricity markets. Energy Convers. Manag. 51(12), 2647-2654 (2010)

19. Moon, J.Y., Shin, K., Jinwoo, P.: Optimization of production scheduling with timedependent and machine-dependent electricity cost for industrial energy efficiency. Int. Adv. Manuf. Technol. 68, 523-535 (2013)

20. Herrmann, C., Thiede, S., Kara, S., Hesselbach, J.: Energy oriented simulation of manufacturing systems - Concept and application. In: CIRP Ann. - Manuf. Technol., vol. 60(1), pp. 45-48 (2011)

21. Thiede, S., Seow, Y., Andersson, J., Johansson, B.: Environmental aspects in manufacturing system modelling and simulation: State of the art and research perspectives. In: CIRP J. Manuf. Sci. Technol., vol. 6(1), pp. 78-87 (2013)

22. Wohlgemuth, V., Page, B., Kreutzer, W.: Combining discrete event simulation and material flow analysis in a component-based approach to industrial environmental protection. Environ. Model. Softw. 21, 1607-1617 (2006)

23. Johansson, B., Skoogh, A., Mani, M., Leong, S.: Discrete event simulation to generate requirements specification for sustainable manufacturing systems design. In: Proceedings of the 9th Workshop on Performance Metrics for Intelligent Systems, pp. 38-42 (2009)

24. Mouzon, G., Yildirim, M.V., Twomey, J.: Operational methods for minimization of energy consumption of manufacturing equipment. Int. J. Prod. Res. 45, 37-41 (2007)

25. Yin, R., Cao, H., Li, H., Sutherland, J.W.: A Process Planning Method for Reduced Carbon Emissions. Int. J. Comput. Integr. Manuf., 1-17 (2013)

26. Sheng, P., Srinivasan, M., Kobayashi, S.: Multi-Objective Process Planning in Environmentally Conscious Manufacturing: A Feature-Based Approach. CIRP Ann. - Manuf. Technol. 44(1), 433-437 (1995)

27. Tan, X.C., Liu, F., Liu, D.C., Zheng, L., Wang, H.Y., Zhang, Y.H.: Research on the diagnosis and improvement method of a process route in an enterprise production process in terms of sustainable development III. Int. J. Adv. Manuf. Technol. 33(11-12), 1256-1262 (2006) 
28. Srinivasan, M., Sheng, P.: Feature-based process planning for environmentally conscious machining: Part 1: micro planning. Rob. Com. Int. Man. 15, 257-270 (1999)

29. Duflou, J.R., Sutherland, J.W., Dornfeld, D., Herrmann, C., Jeswiet, J., Kara, S., Hauschild, M., Kellens, K.: Towards energy and resource efficient manufacturing: A processes and systems approach. CIRP Ann.-Man. Tech. 61, 587-609 (2012)

30. Fysikopoulos, A., Stavropoulos, P., Salonitis, K., Chryssolouris, G.: Energy Efficiency Assessment of Laser Drilling Process. Phys. Procedia 39, 776-783 (2012)

31. Matta, A., Frigerio, N.: Machine Control Policies for Energy Saving in Manufacturing. In: Proc. of the 2013 IEEE CASE, Madison, Wisconsin, USA, pp. 663-668 (2013)

32. Drake, R., Yildirim, M.B., Twomey, J., Bayram, M., Whitman, L., Ahmad, J., Lodhia, P.: Data Collection Framework on Energy Consumption in Manufacturing, Wichita State Univ. Libr. SOAR Shock. Open Access Repos. (2006)

33. Gutowski, T., Murphy, C., Allen, D., Bauer, D., Bras, B., Piwonka, T., Sheng, P., Sutherland, J., Thurston, D., Wolff, E.: Environmentally benign manufacturing: Observations from Japan, Europe and the United States. J. Clean. Prod. 13, 1-17 (2005)

34. Neugebauer, R., Wabner, M., Rentzsch, H., Ihlenfeldt, S.: Structure principles of energy efficient machine tools. CIRP J. Manuf. Sci. Tech. 4(2), 136-147 (2011)

35. Kara, S., Manmek, S., Herrmann, C.: Global manufacturing and the embodied energy of products. CIRP Ann. - Manuf. Technol. 59(1), 29-32 (2010)

36. ENEPLAN: Energy Efficienct Process pLAnning system. The seventh framework program - FoF.NMP.2011-1: The Eco-Factory: cleaner and more resource-efficient production in manufacturing Program, http: / /www. eneplan.eu/

37. Li, W., Winter, M., Kara, S., Herrmann, S.: Eco-efficiency of manufacturing processes: A grinding case. CIRP Ann. - Manuf. Technol. 61(1), 59-62 (2012)

38. Mori, M., Fujishima, M., Inamasu, Y., Oda, Y.: A study on energy efficiency improvement for machine tools. CIRP Ann. - Manuf. Technol. 60, 145-148 (2011)

39. SIEMENS AG.: Energieeffiziente Werkzeugmaschinen mit Sinumerik Ctrl-Energy von Siemens sind sparsam und produktiv (2011),

http://www.siemens.com/press/de/

pressemitteilungen $/$ ?press $=/$ de $/$ pre

40. Gildemeister, A.: DMG MORI (2012),

http://en.dmgmoriseiki.com/sites/en/

41. Eberspächer, P., Verl, A.: Realizing energy reduction of machine tools through a controlintegrated consumption graph-based optimization method. Procedia CIRP (2013) 